Arq. Bras. Med. Vet. Zootec., v.69, n.4, p.815-820, 2017

\title{
Associação de plasma sanguíneo ao tratamento de envenenamento botrópico em equino: relato de caso
}

[Plasma blood associated with the treatment of bothropic poisoning in equine: case report]

\author{
A.C. Camplesi ${ }^{1}$, G.G. Rivera ${ }^{1}$, Y.S. Bonacin ${ }^{1}$, V.B. Paula ${ }^{1}$, J.C. Lacerda Neto ${ }^{1}$, C.F. Moya-Araujo ${ }^{2 *}$
}

${ }^{1}$ Universidade Estadual Paulista "Júlio Mesquita Filho" - Unesp - Jaboticabal, SP

${ }^{2}$ Universidade Estadual Paulista "Júlio Mesquita Filho" - Unesp - Botucatu, SP

\begin{abstract}
RESUMO
O presente trabalho tem por objetivo relatar um caso de envenenamento botrópico em um equino, fêmea, seis anos de idade, da raça Quarto de Milha, pesando $460 \mathrm{~kg}$, que foi atendido no hospital veterinário da FCAV/Unesp, Campus de Jaboticabal, SP. No exame clínico, observou-se aumento bilateral de narina, com extrema sensibilidade ao toque, presença das marcas da presa da serpente na região rostral de focinho, mucosas róseas com petéquias. No exame de sangue, pôde-se detectar alteração no tempo de coagulação sanguínea ( $>30$ minutos). O animal permaneceu internado, sendo instituída a seguinte terapia: soro antiofídico polivalente, transfusão de plasma sanguíneo equino, fluidoterapia intensa, flunixin meglumine e sulfa associado ao trimetoprim. A associação da transfusão de plasma sanguíneo equino ao tratamento convencional foi de extrema importância para correção da coagulopatia causada pelo acidente ofídico. A égua apresentou melhora clínica e resolução do quadro de envenenamento após cinco dias da internação.
\end{abstract}

Palavras-chave: bothrops, acidente ofídico, terapêutica

\begin{abstract}
This study aims to report a case of blood plasma association with the treatment of bothrops poisoning in an equine, female, six years of age, Quarter Horses, weighing $460 \mathrm{~kg}$, which was served in the veterinary hospital of the FCAV/UNESP, Jaboticabal/SP. Clinical examination showed bilateral increase in nostrils, with great sensitivity to touch, presence of snake prey marks the rostral region of the snout, mucous rosy and with petechiae. Blood samples showed changes in blood clotting time (> 30 minutes). The animal remained in hospitalization with the following treatment: polyvalent antivenom, blood plasma transfusion, intensive fluid therapy, flunexim meglumine and sulfa associated with trimethoprim. The association of transfusion equine blood plasma to conventional treatment was extremely important for correction of coagulopathy caused by snakebite. The mare showed clinical improvement and resolution of poisoning symptoms after five days of hospitalization.
\end{abstract}

Keywords: bothrops, snakebites, terapeutic

\section{INTRODUÇÃO}

Existem aproximadamente 3.000 espécies de serpentes no mundo, sendo que $20 \%$ são peçonhentas. Estima-se em humanos, que mais de um milhão de pessoas são picadas por ano, causando cerca de 125.000 mortes no mundo (Thornton, 2014).

Recebido em 21 de setembro de 2016

Aceito em 10 de outubro de 2016

*Autor para correspondência (corresponding author)

E-mail: carlafredrichsen@yahoo.com.br
Os acidentes ofídicos na espécie equina normalmente são provocados por serpentes da família Viperidae, sendo os gêneros Crotalus,Bothrops e Lachesis os mais frequentes. Os envenenamentos por serpentes da família Elapidae (gênero Micrurus) não são descritos em cavalos e provavelmente não ocorrem (Buchanam, 2014).

Os locais de picadas mais comuns em animais de produção são focinho, membros e abdômen. Os 
sinais clínicos se iniciam com sensibilidade dolorosa e edema no local da picada, podendo apresentar petéquias e equimoses na pele. Pequenos pontos de hemorragia, únicos ou duplos, podem sinalizar o local da picada, auxiliando no diagnóstico. O agravamento dos sinais depende do local da picada, do tipo de serpente envolvida e da quantidade de veneno injetada no acidente (Buchanam, 2014; Silva e Lofego, 2006; Sousa et al., 2011).

Para o gênero Bothrops, serpentes conhecidas como jararacas, o veneno tem ação proteolítica (necrosante), coagulante, vasculotóxica e nefrotóxica, que provocam mudanças sistêmicas, além dos sinais significativos no local da picada (Chiacchio et al., 2011). Um dos componentes do veneno é a jararagina, uma metaloproteinase, que se acumula nas proximidades dos vasos. A adsorção ocorre nos componentes celulares, por ligação a estes. Dessa maneira, altera a integridade vascular e induz o sangramento local, um dos principais sinais do envenenamento (Baldo et al., 2010). Além desta ação vasculotóxica, segundo Cominetti et al. (2003), as alterações hemostáticas também são causadas pela ação coagulante, provavelmente por degradação dos fatores da cascata de coagulação, como o II, V,VIII e X.

O protocolo terapêutico após a picada consiste na aplicação de soro antiofídico em dose adequada, por via intravenosa, e fluidoterapia para garantir hidratação adequada, melhorar a perfusão renal, além de fornecer suporte cardiovascular (Lima et al., 2013).

A transfusão de sangue e/ou de seus derivados pode ser utilizada em animais como auxílio terapêutico em enfermidades com transtornos de coagulação. $\mathrm{O}$ plasma sanguíneo colhido, separado e armazenado a $-18^{\circ} \mathrm{C}$ é denominado plasma fresco congelado. $\mathrm{O}$ processo de congelação protege os fatores de coagulação lábeis, e, portanto, contém todos os fatores de coagulação, além de todas as proteínas plasmáticas e as imunoglobulinas. O plasma fresco congelado mantém suas características por um a dois anos, quando armazenado adequadamente (Hunt e Moore, 1990; Collatos, 1997).

O presente trabalho tem por objetivo relatar um caso de envenenamento botrópico em equino, que foi tratado com soro antiofídico polivalente associado à transfusão de plasma sanguíneo equino.

\section{CASUÍSTICA}

Foi encaminhado ao hospital veterinário (HV) da Faculdade de Ciências Agrárias e Veterinárias um equino, fêmea, seis anos de idade, da raça Quarto de Milha, vacinada contra tétano há um mês, pesando $460 \mathrm{~kg}$, com histórico de picada de serpente em região de narina.

O proprietário relatou que o médico veterinário responsável foi chamado na propriedade durante a noite, e observou a presença de intenso edema rostral em ambas as narinas, além da presença da marca das presas da serpente em região de focinho, o que auxiliou o estabelecimento do diagnóstico de acidente ofídico. Foram administrados três frascos de soro antiofídico polivalente liofilizado, sendo um aplicado na via intravenosa e dois aplicados pela via intramuscular, fenilbutazona $\quad(2,2 \mathrm{mg} / \mathrm{kg}$, intravenosa - IV), flunixin meglumine $(1,1 \mathrm{mg} / \mathrm{kg}, \mathrm{IV})$, dexametasona $(0,2 \mathrm{mg} / \mathrm{kg}, \mathrm{IV}) \mathrm{e}$ furosemida $(0,5 \mathrm{mg} / \mathrm{kg}$, IV), aplicados em dose única. Ao longo da madrugada, foram administrados 23 litros de fluidoterapia, intercalando soluções de ringer lactato e solução de cloreto de sódio $0,9 \%$, IV. No dia seguinte, o animal foi encaminhado ao HV para continuidade do tratamento.

Ao exame físico de admissão ( $\mathrm{D} 0=$ dia 0 ), observou-se na inspeção um aumento bilateral de narina, com extrema sensibilidade ao toque, e a presença das marcas da presa da serpente na região rostral de focinho (Fig. 1). A frequência cardíaca aferida foi $44 \mathrm{bpm}$, frequência respiratória $20 \mathrm{mpm}$, temperatura corporal de $37,9^{\circ} \mathrm{C}$, mucosas róseas, porém com a presença de petéquias. Colheu-se amostra de sangue por venopunção da jugular para realização de exames laboratoriais.

Iniciou-se a fluidoterapia intravenosa com solução de cloreto de sódio a $0,9 \%(15 \mathrm{~mL} / \mathrm{kg} / \mathrm{h})$, totalizando 55 litros. Ao se colocar o catéter na jugular, observou-se dificuldade de coagulação sanguínea, visto que o sangue ficou escorrendo pelo orifício causado por este material. Ao longo da fluidoterapia, dois catéteres foram perdidos, sendo necessária a colocação de outro, cujo local de inserção não parava de sangrar. Conseguiu-se executar hemostasia parcial, com o uso de compressa de gelo e compressão local. 


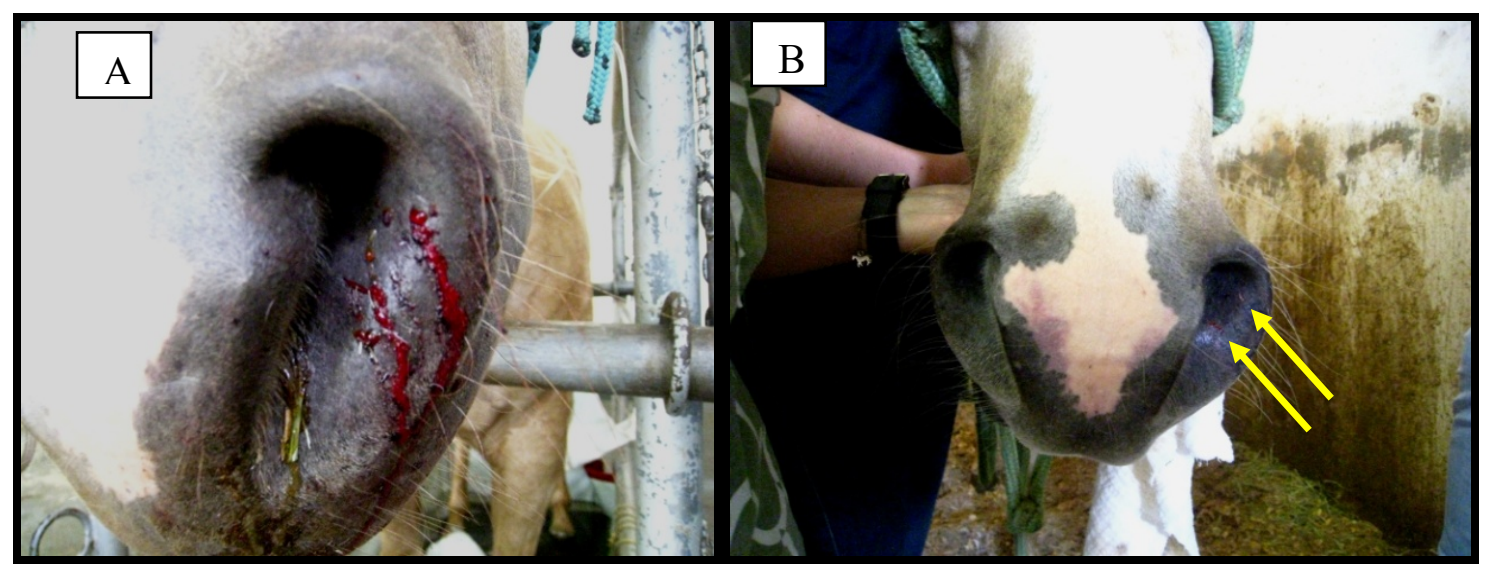

Figura 1. Fotografia da narina da égua picada por serpente com destaque (A) para o sangramento e o edema e (B) para as marcas da presa (setas).

Os resultados dos exames laboratoriais (Tab. 1 e 2), principalmente o tempo de coagulação com resultado de sangue incoagulável, associado à clínica do animal, com alterações significativas no local da picada e hemorragias, confirmaram o diagnóstico de envenenamento botrópico.

Com o diagnóstico, introduziu-se à terapêutica, com a administração de flunixin meglumine, na dose de $1,1 \mathrm{mg} / \mathrm{kg}$, IV, a cada 24 horas. No dia seguinte (D1), foram feitos 15 litros de solução de cloreto de sódio a $0,9 \%(15 \mathrm{~mL} / \mathrm{kg} / \mathrm{h})$, IV. Nova colheita de sangue foi realizada e o resultado do tempo de coagulação ainda permanecia alterado (incoagulável). Foi administrado mais um frasco de soro antiofídico polivalente liofilizado, IV, e 500mg de hidrocortisona, IV. Observou-se que os orifícios dos catéteres voltaram a sangrar, mas a hemostasia não foi obtida com sucesso, com o uso de compressa de gelo e compressão local.
Foi então solicitado ao proprietário a aquisição de plasma sanguíneo equino fresco congelado $\left(\right.$ CenterVet $^{\circledR}$, São Paulo-SP, Brasil), que chegou no D3.

Devido à trombocitopenia severa e a alterações na coagulação, resolveu-se administrar um litro de plasma sanguíneo equino, IV, seguido de 12 litros de solução de cloreto de sódio a $0,9 \%$, $(10 \mathrm{~mL} / \mathrm{kg} / \mathrm{h}, \mathrm{IV})$. Nesse momento, também teve início a aplicação de sulfadoxina associada ao trimetoprim $(25 \mathrm{mg} / \mathrm{kg}$, IV), a cada 24 horas, durante sete dias consecutivos. À tarde, foram utilizados vários métodos de hemostasia, como compressão local, uso de compressa de gelo, esponja específica de estancar sangue (Hemospon $^{\circledR}$, Technew, Rio de Janeiro, RJ, Brasil), solução à base de iodo, percloreto de ferro e triclorfon $\left(\right.$ Friezol $^{\circledR}$, Pinus, Jundiaí, SP, Brasil), sendo efetivo o pinçamento do ponto de hemorragia com pinças Halsted para hemostasia.

Tabela 1. Dados dos exames laboratoriais realizados nos dias em que o animal permaneceu internado, sendo D0 o dia em que o animal deu entrada no HV

\begin{tabular}{|c|c|c|c|c|c|c|c|c|c|c|c|}
\hline Dia & $\begin{array}{l}\mathrm{He} \\
\times 10^{6}\end{array}$ & $\begin{array}{l}\mathrm{Ht} \\
\%\end{array}$ & $\begin{array}{c}\mathrm{Le} \\
\times 10^{3}\end{array}$ & $\begin{array}{c}\text { NB } \\
\%\end{array}$ & $\begin{array}{c}\text { NS } \\
\%\end{array}$ & $\begin{array}{c}\text { Linf. } \\
\%\end{array}$ & $\begin{array}{c}\text { Mon. } \\
\%\end{array}$ & Plaq. & $\begin{array}{l}\text { Tempo de } \\
\text { coagulação }\end{array}$ & $\begin{array}{c}\mathrm{PT} \\
\mathrm{g} / \mathrm{dL}\end{array}$ & $\begin{array}{c}\text { Fibrinog. } \\
\mathrm{mg} / \mathrm{dL}\end{array}$ \\
\hline $\mathbf{0}$ & 5,47 & 24,6 & 9600 & 00 & 89 & 07 & 04 & 94000 & $>30$ min. $^{*}$ & 4,2 & 200 \\
\hline 1 & 5,1 & 22,8 & 10200 & 00 & 82 & 15 & 03 & 79000 & $>30$ min. $^{*}$ & 5,0 & 200 \\
\hline 2 & 4,74 & 21,5 & 6700 & 00 & 72 & 26 & 01 & 47000 & $>30 \mathrm{~min}^{*}$ & 4,8 & 200 \\
\hline 3 & 6,8 & 29 & 7300 & 00 & 64 & 35 & 01 & 69000 & $>30$ min. $^{*}$ & 5,8 & 400 \\
\hline 4 & 5,23 & 22,7 & 8700 & 00 & 76 & 22 & 02 & 35000 & $20 \mathrm{~min}$. & 5,4 & 400 \\
\hline 7 & 5,15 & 22,8 & 20400 & 00 & 76 & 20 & 02 & 76000 & $10 \mathrm{~min}$. & 6,4 & 400 \\
\hline 9 & 5,19 & 22,9 & 19000 & 00 & 84 & 10 & 06 & 177000 & ---- & 6,4 & 400 \\
\hline 15 & 5,56 & 24,2 & 13200 & 00 & 86 & 10 & 02 & 217000 & ---- & 6,8 & 200 \\
\hline
\end{tabular}

* incoagulável. 
Tabela 2. Dados dos exames bioquímicos realizados nos dias em que o animal permaneceu internado, sendo D0 o dia em que o animal deu entrada no HV

\begin{tabular}{ccccccccc}
\hline Dia & $\begin{array}{c}\text { Ureia } \\
\mathrm{mg} / \mathrm{dL}\end{array}$ & $\begin{array}{c}\text { Creatinina } \\
\mathrm{mg} / \mathrm{dL}\end{array}$ & $\begin{array}{c}\mathrm{AST} \\
\mathrm{UI} / \mathrm{L}\end{array}$ & $\begin{array}{c}\mathrm{GGT} \\
\mathrm{UI} / \mathrm{L}\end{array}$ & $\begin{array}{c}\text { FA } \\
\mathrm{UI} / \mathrm{L}\end{array}$ & $\begin{array}{c}\text { Albumina } \\
\mathrm{g} / \mathrm{dL}\end{array}$ & $\begin{array}{c}\mathrm{BD} \\
\mathrm{mg} / \mathrm{dL}\end{array}$ & $\begin{array}{c}\mathrm{BI}^{* *} \\
\mathrm{mg} / \mathrm{dL}\end{array}$ \\
\hline 0 & 69 & 2,2 & 104 & 15 & 124 & 2,23 & 0,45 & 3,13 \\
3 & 51 & 2,8 & 319 & 22 & 165 & 2,48 & ---- & ---- \\
7 & 31 & 1,8 & 172 & 22 & 257 & --- & 0,38 & 2,38 \\
9 & 32 & 1,5 & 178 & 38 & 257 & 2,25 & 0,31 & 1,42 \\
15 & 36 & 1,6 & 146 & 76 & 240 & 1,53 & 0,20 & 1,49 \\
\hline
\end{tabular}

Após a administração do plasma (D3), o animal não mais apresentou hemorragias nos pontos de inserção do catéter e, no dia seguinte, o tempo de coagulação já apresentou melhora. Ao longo dos dias no $\mathrm{HV}$, a paciente demonstrou melhora significativa em relação ao edema, observandose regressão a cada dia e diminuição da sensibilidade dolorosa, bem como o retorno do apetite de forma progressiva, conforme o edema da face diminuía. Com a evolução positiva nos últimos dias, o animal teve o tratamento para as alterações coagulativas causadas pelo acidente ofídico suspenso cinco dias após ter dado entrada no $\mathrm{HV}$, com redução total do edema da narina.

Durante a internação, observou-se um aumento significativo e progressivo de ambos os membros torácicos no D6, desenvolvendo-se, assim, um edema bilateral dos membros. No hemograma, foi observado um aumento dos leucócitos e do fibrinogênio. Foi realizada massagem local com DMSO e utilizou-se faixa compressiva para auxiliar a drenagem linfática do animal, bem como fez-se uso constante de liga de descanso associado à soltura do animal no piquete. Dessa maneira, com a melhora clínica desse quadro, o animal obteve alta hospitalar no D16.

\section{DISCUSSÃO}

Segundo Bicudo (1994), em levantamento de 149 casos de acidentes ofídicos, 85,90\% deles eram causados por serpentes do gênero Bothrops, $17,18 \%$ dos quais ocorreram em equinos, perdendo apenas para os caninos, que são os animais mais acometidos $(80,46 \%)$ por esse gênero de ofídio. Sakate (2008) relata que todos os mamíferos são susceptíveis ao veneno botrópico, porém, em ordem de sensibilidade, a espécie equina é a mais sensível. Esse autor refere-se também ao fato de que os equinos normalmente são afetados na região da cabeça, concordando com o local da picada deste relato.
Os sinais clínicos mais comuns descritos são edema próximo ao local da picada com intensa sensibilidade dolorosa, petéquias, equimoses, e hemorragias com alto índice de mortalidade (Buchanam, 2014; Silva e Lofego, 2006; Sousa et al., 2011). O animal em estudo apresentou sinais clínicos semelhantes aos descritos na literatura. As lesões identificadas são provocadas pelas ações proteolítica, coagulante $\mathrm{e}$ hemorrágica do veneno, que possui mais de 20 substâncias, as quais atuam causando inflamação, dano ao epitélio vascular, incoagulabilidade sanguínea e necrose local (Baldo et al., 2010).

Os resultados dos exames laboratoriais mostraram anemia normocítica, normocrômica e trombocitopenia severa persistente, corroborando os achados de Sousa et al. (2011), ocasionadas provavelmente pelo quadro hemorrágico instalado. Na bioquímica sérica, foi observada elevação de ureia e creatinina nos dois primeiros dias, com indicação de ser de origem pré-renal, pois esses valores se normalizaram após a fluidoterapia intensa realizada nos primeiros dias. Sousa et al. (2011) também observaram aumento nos níveis de ureia e creatinina séricas. $\mathrm{O}$ tempo de coagulação mostrou sangue incoagulável, bastante característico da clínica do acidente ofídico. Com base nos resultados dos exames laboratoriais e nos sinais clínicos apresentados, pode-se chegar ao diagnóstico de envenenamento botrópico, assim como descrito por Lima et al. (2013).

O diagnóstico em animais de produção é dificultado, pois, em muitos casos, o proprietário ou o profissional não estão presentes no momento do acidente. O edema no local da picada, as hemorragias, bem como os dados laboratoriais, particularmente $\mathrm{o}$ aumento no tempo de coagulação, confirmam a suspeita clínica de acidente botrópico (Sakate, 2008). 
Todos esses dados estavam presentes e foram de grande valia no diagnóstico do caso atendido.

A ação coagulante do veneno é conhecida como "tipo trombina" e é decorrente da transformação do fibrinogênio em fibrina e da ativação e consequente consumo de outros fatores de coagulação (II, V, VII e X), que, somados à moderada trombocitopenia que se instala, interfere na hemostasia. $\mathrm{O}$ consumo dos fatores de coagulação causa a incoagulabilidade do sangue no paciente. O quadro hemorrágico é muito comum nos acidentes botrópicos e é atribuído à ação vasculotóxica das hemorraginas, que provocam ruptura capilar (Sakate, 2008). Essas alterações na coagulação foram observadas no caso relatado, no qual o tempo de coagulação mantinha-se muito alterado, optando-se, então, pela administração de plasma sanguíneo equino, que contém todos os fatores de coagulação e é indicado como auxiliar ao tratamento ou à prevenção de sangramento em pacientes com deficiências de múltiplos fatores de coagulação (Hunt e Moore, 1990; Collatos, 1997). Dessa maneira, observou-se diminuição da hemorragia e normalização dos exames laboratoriais. A incoagulabilidade sanguínea só obteve melhora após o uso do plasma, o qual repôs os fatores de coagulação consumidos pela ação do veneno.

A eficácia do tratamento depende essencialmente da aplicação da dose adequada e de sua realização em tempo hábil. Deve-se, o mais precocemente possível, fazer a administração de soro específico para o gênero Bothrops (soro antibotrópico) ou soro polivalente (soro antiofídico que contenha soro antibotrópico), na dose que neutralize, no mínimo, $100 \mathrm{mg}$ do veneno botrópico (Rosenfeld, 1991). Caso haja hemorragia intensa, é indicada transfusão de plasma específico para a espécie, com o intuito de repor os fatores de coagulação consumidos e, dessa maneira, diminuir a ocorrência de mais focos hemorrágicos (Manual..., 2001). Correa et al. (2011) relataram um caso de acidente ofídico em equino, cujo tratamento preconizado foi a aplicação do soro antiofídico associado à transfusão de sangue, devido ao quadro de incoagulabilidade sanguínea apresentado pelo animal, com a melhora clínica dele.

O tratamento realizado por colega ainda na propriedade, antes de encaminhar o animal para o atendimento, com a administração do soro antiofídico no dia da picada, foi importante na sobrevida do animal, pois o tratamento precoce é fundamental. Contudo, por ter administrado somente um frasco pela via intravenosa, a dose de anticorpos biodisponíveis para neutralizar o veneno provavelmente não foi suficiente para bloquear todos os efeitos tóxicos. Segundo Sakate (2008), administrações adicionais com a metade da dose inicial são indicadas quando o sangue permanecer incoagulável após 12 horas do início do tratamento. Baseado nisso, foi realizada uma segunda aplicação de soro antiofídico polivalente, por via intravenosa, na paciente, no segundo dia em que se encontrava sob tratamento no $\mathrm{HV}$, devido à observação da incoagulabilidade sanguínea. Porém, como já se haviam passado mais de 24 horas do acidente, os fatores de coagulação já haviam sido consumidos, e só o soro antiofídico não foi suficiente para conter a hemorragia que o animal apresentava.

A boa evolução clínica do animal ocorreu devido à realização do tratamento adequado, administrando-se o soro antiofídico polivalente com a associação de plasma sanguíneo, o qual fez a reposição dos fatores de coagulação que provavelmente foram consumidos pela ação coagulante do veneno da serpente (Cominetti et al., 2003), evitando-se, dessa forma, que o animal viesse a óbito por hemorragia. Lima et al. (2013) relataram um caso de associação de transfusão sanguínea em um equino picado por serpente, o qual apresentava volume globular de $10 \%$, em razão da coagulopatia e da diátese hemorrágica, contudo o animal veio a óbito dois dias após o início do tratamento. A transfusão de plasma fresco congelado é indicada, por alguns autores, para controle dos distúrbios hemorrágicos (Nogueira, 2011).

A escolha pela transfusão de plasma, no presente caso, foi influenciada pelos exames laboratoriais, uma vez que o hematócrito do animal não estava diminuído a ponto de indicar a transfusão de sangue total, porém a proteína total plasmática se encontrava abaixo dos valores de referência para a espécie, bem como a incoagulabilidade sanguínea, que foi evidenciada no teste de tempo de coagulação.

A terapia com furosemida, como foi feita na propriedade, não é recomendada, pois não bloqueia os efeitos do veneno no organismo e 
pode agravar o quadro do paciente, causando desidratação.

Deve-se sempre considerar a utilização de soro antitetânico no tratamento de acidente ofídico em equinos, devido à grande susceptibilidade da espécie ao tétano (Buchanam, 2014). No presente relato, essa forma de terapia não foi realizada, pois o proprietário relatou que o animal havia sido vacinado contra tétano um mês antes do acidente, estando provavelmente imunizado.

\section{CONCLUSÃO}

A administração do soro antibotrópico é fundamental para neutralizar as alterações hemostáticas que ocorrem nesse tipo de envenenamento e impedir o agravamento dos sinais sistêmicos. A associação do plasma sanguíneo equino ao tratamento de envenenamento botrópico convencional se mostrou interessante, auxiliando nas alterações de coagulação sanguínea, uma vez que o animal apresentou evidente melhora clínica. Assim, a transfusão de plasma pode ser um item auxiliar a ser abordado no suporte ao paciente que sofre um acidente ofídico.

\section{REFERÊNCIAS}

BALDO, C.; JAMORA, C.; YAMANOUYE, N. et al. Mechanisms of vascular damage by hemorrhagic snake venom metalloproteinases: tissue distribution and in situ hydrolysis. Negl. Trop. Dis., v.4, p.1-10, 2010.

BICUDO, P.L. Acidentes ofídicos em medicina veterinária. In: BARRAVIERA, B. (Ed.). Venenos animais: uma visão integrada. Rio de Janeiro: EPUC, 1994. p.375-387.

BUCHANAM, B.R. Snake envenomation. In: ORSINI, J.A.; DIVERS, T.J. (Eds.). Equine emergencies: treatment and procedures. 4.ed. Cambridge: Elsevier, 2014. p.724-727.

CHIACCHIO, S.B.; MARTINS, G.T.B.; AMORIM, R.M. et al. Triple bothropic envenomation in horses caused by a single snake. J. Venom. Anim. Toxins, v.17, p.111-117, 2011
COLlatos, C. Hemostatic dysfunction. In: ROBINSON, N.E. Current therapy in equine medicine. 4.ed. Philadelphia: W.B. Saunders Company, 1997. p. 286-289.

COMINETTI, M.R.; RIBEIRO, J.U.; FOX, J.W.; SELISTRE-DE-ARAUJO, H.S. A new dimeric metalloproteinase/disintegrin from the Bothrops alternatus snake venom that interacts with $\alpha 2 \beta 1$ integrin. Arch. Biochem. Biophys., v.416, p.171-179, 2003.

CORREA, R.R.; FRIAS, N.C.; SILVA JR., L.R. et al. Acidente ofídico em equino - relato de caso. Rev. Educ. Cont. Med. Vet. Zootec., v.9, p.55-56, 2011.

HUNT, E., MOORE, J.S. Use of blood and blood products. Vet. Clin. N. Am. Food Anim. Pract., v.6, p.133-147, 1990.

LIMA，J.T.B.; PATRÍCIO, L.A.M.M.; FARIAS, A.F.A.; BAPTISTA FILHO, L.C.F. Acidente ofídico em equino: relato de caso. JORNADA DE ENSINO, PESQUISA E EXTENSÃO, 8., 2013, Pelotas. Anais... Pelotas: JEPEX, 2013. p.1-3.

MANUAL de diagnóstico e tratamento de acidentes por animais peçonhentos. 2ed. Brasília: Funasa, 2001. p.120.

NOGUEIRA, R.M.B. Lagartas e serpentes. In: NOGUEIRA, R.M.B.; ANDRADE, S.F. Manual de toxicologia veterinária. São Paulo: Roca, 2011. $1242 \mathrm{p}$.

ROSENFELD, G. Acidentes por animais peçonhentos: serpentes, aranhas, escorpiões. In: VERONESI, R. (Ed.). Doenças infeciosas e parasitárias. 8ed. Rio de Janeiro: Guanabara Koogan, 1991. p.951-962.

SAKATE, M. Zootoxinas. In: SPINOSA, H.S.; GÓRNIAK, S.L.; PALERMO-NETO, J. (Eds.). Toxicologia aplicada à medicina veterinária. Barueri: Manole, 2008. p.209-251.

SILVA, E.R.O.; LOFEGO, A.C. Acidentes ofídicos na região de São José do Rio Preto. Rev. UNORP, v.13, p.127-133, 2006.

SOUSA, G.M.; TOKARNIA, C.H.; BRITO, M.F. et al. Aspectos clínicos-patológicos do envenenamento botrópico experimental em equinos. Pesqui. Vet. Bras., v.31, p.773-780, 2011.

THORNTON, S.L. Snakes. In: WEXLER, P. (Ed.). Encyclopedia of toxicology. 3ed. Cambridge: Elsevier, 2014. p.310-312. 